\section{How green is your smartphone?}

\begin{abstract}
Toby Miller \& Richard Maxwell
(2020). How Green is Your

Smartphone? Cambridge: Polity
\end{abstract}

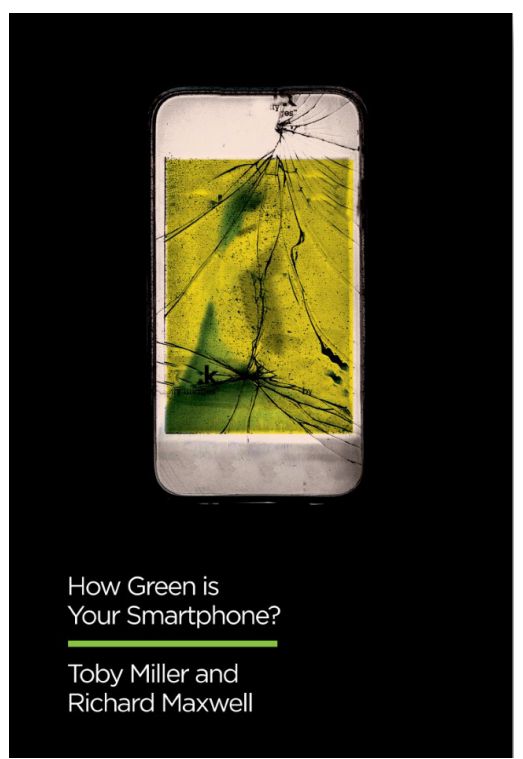

Los teléfonos inteligentes o smartphones son parte del día a día de gran cantidad de la población mundial, alcanzando cifras de penetración de más del 95 por ciento de usuarios en países como Estados Unidos. La industria digital presenta esta tecnología como garante del desarrollo social y la plenitud, mientras que las consecuencias medioambientales y sociales de su arrollador éxito quedan fuera del debate público y académico. Richard Maxwell y Toby Miller reflexionan, desde el marco de las Ciencias de la Comunicación, sobre el impacto material y social de esta tecnología con la convicción de que pequeños cambios en nuestra vida digital pueden contribuir a la construcción de un marco de comunicación sostenible.
Los teléfonos inteligentes se han convertido en parte indiscutible de nuestro día a día, con efectos beneficiosos y otros no tanto. Los sociólogos tienen sentimientos encontrados cuando se trata de analizar este dispositivo: por un lado, algunos consideran que amplía los canales de comunicación, mejora la seguridad personal, facilita el intercambio cultural o fortalece las relaciones personales; por otro lado, sería culpable de aumentar la fractura social o generar formas de desigualdad - si no tienes uno en tus manos el acceso a los nuevos modos de sociabilidad del siglo XXI se puede ver más que comprometido- por no mencionar la presión psicológica generada por la necesidad de estar constantemente conectado.

En España, su cuota de mercado es del 92 por ciento, superando a la media europea, aunque Alemania, Italia, Francia y Reino Unido no están tampoco lejos de la cifra ganadora del 95 por ciento de norteamericanos que tiene un celular. Asimismo, la International Communication Union (ITU) subraya la importancia de este dispositivo para el desarrollo económico de Asia, los Estados Árabes, África y Latinoamérica.

El teléfono inteligente ha sido encumbrado como emblema del progreso tecnológico y la abundancia durante más de una década gracias a una promoción incesante orquestada por las grandes empresas manufactureras. En este sentido la nueva obra de Richard Maxwell y Toby Miller, How Green is Your Smartphone?, analiza críticamente las consecuencias medioambientales y laborales que el éxito arrollador de este dispositivo ha traído consigo, exhortando a los lectores y lectoras a ser más inteligentes que sus teléfonos inteligentes.
Maxwell y Miller subrayan que el objetivo de este volumen no es avergonzar a los usuarios o promover la desaparición del smartphone, sino explicar los riesgos ecológicos y sociales asociados a estos dispositivos y discernir vías para aminorarlos. En síntesis, definir un nuevo papel para el smartphone dentro de un marco de comunicación sostenible. El libro ha sido escrito desde la convicción de que la forma en la que se reflexiona sobre el mundo digital puede contribuir a una nueva comprensión de lo que, de acuerdo con los autores, constituye una vida plena: aquella que prioriza la biosfera, la ecología y, en definitiva, el equilibrio entre los seres humanos y los sistemas naturales.

How Green is Your Smartphone? está dividido en tres capítulos y un epílogo a modo de conclusión, en los cuales se discuten en profundidad las siguientes temáticas: el capítulo primero, Outsmart your smartphone, alude a la radiación por radiofrecuencia generada por los teléfonos inteligentes la cual, según diversos estudios, causaría graves riesgos para la salud. Los teléfonos móviles no deben superar niveles de radiación de 1.6 watios por kilogramo, límite que puede verse traspasado cuando el dispositivo está en contacto con nuestro cuerpo. Los autores discuten las razones por las que el usuario promedio desconoce esta información y las dificultades existentes para acceder a ella. En segundo lugar, se realiza una panorámica sobre las adicciones vinculadas a estas tecnologías y sus efectos, entre ellos el creciente número de accidentes de tráfico en los que ha intervenido el uso del celular.

El título de la segunda sección de la obra es a la vez uno de los pilares básicos para fomentar un consumo 
sostenible de teléfonos inteligentes: The greenest smartphone is the one you already own. Este capítulo se centra en el impacto material de las TIC. Un apartado que explora los peligros inherentes a la extracción de materias primas necesarias para la fabricación de los dispositivos, así como las misérrimas condiciones laborales a las que están expuestos los trabajadores y trabajadoras de esta industria. Posteriormente, se examina la gran demanda de energía y recursos naturales necesarios para la manufacturación de los móviles y el funcionamiento de sus aplicaciones. Efectivamente, si se combinan las emisiones procedentes de la fabricación y la producción de la electricidad necesaria para alimentar las redes de conexión y centros de datos, los smartphones y plataformas similares serían responsables del 1.4 por ciento de las emisiones globales de gases de efecto invernadero.

Mientras que el impacto medioambiental de la elaboración de estos dispositivos es muy alto, el consumo de su batería lo contrarresta parcialmente, pues el perfeccionamiento tecnológico ha traído al mercado smartphones cuyo gasto energético es cada vez menor. Por ello, los autores nos invitan a mantener nuestro teléfono móvil el máximo de tiempo posible y cambiarlo sólo en el caso de que sea irreparable.

En promedio, se renueva este dispositivo cada 2 años, lo que supone que 2800 millones de personas cambian de teléfono a escala global en ese reducido período de tiempo. Esta alta tasa de sustitución de los terminales tiene efectos perniciosos para el medioambiente y los seres humanos no sólo con su manufacturación, sino también al final de su vida útil: los smartphones ocupan progresivamente un papel más destacado en los crecientes flujos de basura electrónica, estimándose su presencia en un 10 por ciento del total de este tipo de residuos. Una cuestión importante si se tiene en cuenta que mucha de la basura electrónica es trasladada a países empobrecidos de forma ilegal oculta como bienes de segunda mano, para acabar en vertederos incontrolados cuyo daño a la población y sistemas naturales aledaños es casi irreparable.

Por último, el capítulo titulado $\mathrm{Ca}$ lling bullshit on anti-science propaganda discurre sobre las políticas de relaciones públicas orientadas a generar confusión sobre los problemas ecológicos y de salud que estas tecnologías acarrean. Métodos que son equiparados a las estrategias de comunicación seguidas previamente por la industria tabacalera, las cuales se centraron en minimizar, y en muchos casos ocultar, los riesgos derivados del consumo de tabaco. En este sentido, los autores nos recomiendan poner en práctica el principio de precaución en nuestra relación con los smartphones, es decir, si no sabemos si una tecnología nos puede dañar, es mejor no usarla.

El epílogo es una revisión general de las ideas expuestas a lo largo del libro y un punto de partida para dibujar una relación más sostenible con los smartphones. Con este fin, se hace referencia al Fairphone, un producto de telefonía para consumidores que buscan tecnología respetuosa con los derechos de los trabajadores y el medioambiente $y$, en definitiva, un ejemplo a seguir por las grandes manufactureras. Maxwell y Miller invitan a apoyar a organizaciones que luchan por una industria electrónica justa, tales como el Centro de Reflexión y Acción Laboral en México o Good Electronics en Ámsterdam, entre otras muchas. Finalmente, los autores animan a observar el teléfono móvil desde una nueva perspectiva, aquella que conecta este dispositivo con sistemas naturales y los trabajadores involucrados en su fabricación. En síntesis, promover un consumo más sostenible de los smartphones es contribuir tanto al desarrollo de una sociedad igualitaria, como al imprescindible cuidado de nuestro planeta.

How Green is Your Smartphone? es la última contribución de dos destacados académicos que, desde el terreno de las Ciencias de la Comunicación, han sido pioneros en el estudio del impacto material de las TIC. Juntos han publicado numerosos artículos y trabajos dedicados a esta temática entre los que destaca Greening the Media (2012), una obra que muestra el impacto material de la industria mediática aportando datos históricos, económicos y medioambientales. Mientras Greening the Media es quizá un texto menos accesible por la prodigalidad de datos y diversidad temática, How Green is Your Smartphone? logra, sin perder un ápice de rigurosidad, motivar una lectura dinámica, abierta a todos aquellos ciudadanos y ciudadanas interesados en un consumo mediático sostenible.

\section{Referencias}

Maxwell, R. \& Miller, T. (2012). Greening the media. New York: Oxford University Press.

\section{Javier González de Eusebio}

Universidad Rey Juan Carlos, España j.gonzalezde.2017dalumnos.urjc.es 